In support of the conclusion that the presence of uronic groupings could be inferred from the rate of evolution of carbon dioxide, it was further established that the plant celluloses were not homogeneous with respect to groupings giving rise to carbon dioxide, and that mild acid and alkaline treatments effected a reduction in carbon dioxide yield out of all proportion to loss of weight. The following figures were obtained for Canadian spruce cellulose (carbon dioxide yield $=0.41$ per cent).

(1) Residue after extraction with hot 5 per cent sulphuric acid for 1 hour, 87.34 per cent; carbon dioxide yield, $0 \cdot 26$ per cent.

(2) Residue after extraction with cold 4 per cent caustic soda for 2 hours, 86.40 per cent; carbon dioxide yield, $0 \cdot 23$ per cent.

Carbon dioxide yield on original basis from (1) $=0.22$ per cent. Carbon dioxide yield on original basis from $(2)=0 \cdot 20$ per cent.

While no quantitative significance in terms of uronic content can be attached to very small yields of carbon dioxide from polysaccharides, the development of the procedure outlined above may permit of the demonstration of the presence of uronic groupings with a reasonable degree of certainty.

$$
\begin{aligned}
& \text { Agronomy Department, } \\
& \text { Iowa State College, } \\
& \text { Ames, Iowa. } \\
& \text { Dec. } 30 \text {. } \\
& { }^{1} \text { Campbell, W. G., Hirst, E. L., and Young, G. T., NATURE, 142, } \\
& 912 \text { (1938). } \\
& { }^{2} \text { Norman, A. G., and Martin, J. T., Biochem. J., 24, } 649 \text { (1930). }
\end{aligned}
$$

\section{A Rapid Visual Test for Vitamin A Deficiency}

A RAPID visual test for vitamin A deficiency has been described by Gridgeman and Wilkinson ${ }^{1}$, by Haines $^{2}$, and recently by Pett ${ }^{3}$. In this method the patient is first asked to view a strong light (of intensity $I$ ), for a standard time $T$. Then this light is suddenly switched off and the time $t$ required to see a dim light of intensity $i$ is noted. An excessively high value of $t$ is taken to indicate abnormality.

For the past six months I have been studying this method with the view of finding a standard method which will : $(a)$ give maximum discrimination between normals and abnormals; (b) be applicable to uneducated people and children; $(c)$ be capable of being rapidly carried out by an unskilled observer.

The most important difficulty is due to the fact that the time $t$ can be largely influenced by factors such as intelligence, education and nervousness, as well as by vitamin A deficiency.

From my results it appears that: $(a)$ if the in. tensity $I$ is greater than about 100 foot-candles, the patient closes the eyes or is troubled with afterimage; (b) to bring the eye to a definite state and to give maximum discrimination, $T$ must be at least 150 seconds.

Since some time must be spent in making the patient accustomed to the apparatus, I do not think that a reliable indication can be obtained in less than five minutes. At present I make three tests with values of $T$ at $30,60,150$ sec. respectively, the total time being 7 minutes. The first two serve to make the patient accustomed to the apparatus. Also an abnormal, in addition to showing a long time $(t)$ on the last test, usually shows a considerable difference between the second and third tests. Unintelligent or nervous normals, on the other hand, may improve between the second and third tests.
The patient has to say which of four letters he sees $(N, Z, T, X)$. The letters are about two inches high and are viewed from 16 inches. Objects of similar size are used for children and illiterates, so that ordinary errors of vision do not affect the result.

This work is being continued by Miss E. J. PowerSteele, by whom the detailed results will be published.

Trinity College,

R. W. Ditchburn. Dublin.

${ }^{1}$ Lancet, i, 905 (April 16, 1938).

Trans. Ophth. Soc., 57, Part 1 (1938).

${ }^{3}$ NATURE, 143, 23 (1939).

A Specific Factor in Extracts of the Choroid Plexus Influencing the Permeability of the Myelencephalic Roof

WE have shown in earlier experiments that in chick embryos the spread of cerebrospinal fluid from the neural canal to the periaxial spaces is coincident with the development of the choroid plexuses ${ }^{1}$, and that in rabbit, rat and guinea pig embryos, extra. cerebral spread of cerebrospinal fluid can be induced when a hypertonic saline solution is injected into the blood stream only after the choroid plexuses are differentiated ${ }^{2}$.

In recent experiments we have shown that extracts of the choroid plexus of the rabbit, dog, cow, sheep and guinea pig contain a factor which has the following properties :

(1) It increases the intradermal spread of dyes to a degree commensurate with that of the spreading factor isolated from mammalian testis by $\mathrm{McClean}^{3}$ and investigated by Hoffman and Duran-Reynals, Claude and Duran-Reynals and others.

(2) It is species specific, that is, the choroid plexus extract of rabbit gives in the rabbit a much wider dermal spread than the choroid plexus extracts of cow, sheep and dog; the choroid plexus extract of the dog produces its most extensive spread in the dog.

(3) Stale extracts are usually less potent than fresh extracts.

(4) By injecting chicken choroid plexus extract into the central canal of the nervous system we were able to anticipate the peri-pariaxial spread of cerebrospinal fluid. In non-injected chick embryos, the first extra-cerebral spread of fluid is seen at 7 days through the anterior membranous area of the myelencephalie roof, coincident with the development of the choroid plexus in the lateral and third ventricles. In injected chick embryos there was a quite marked extra-cerebral spread at five days, that is, two days earlier than the appearance of the choroid plexus, and a slight spread was observed in four-day embryos. Cow choroid plexus and rabbit testis extracts increased the permeability of the membranous areas

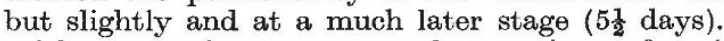

These experiments suggest that a primary function of the glandular epithelium of the choroid plexus is to elaborate a factor which renders permeable the membranous areas of the myelencephalic roof and thus initiates the extra-cerebral escape of the fluid from the central canal.

$W_{e}$ have found recently that extracts of the ciliary body contain a similar spreading factor, an observation which might throw light on the etiology of senile glaucoma.

\section{Department of Medicine, \\ University of Liverpool. \\ HenRy CoHen.} Jan. 10.

${ }^{1}$ Cohen, H., and Davies, S., J. Anat., 62, 23 (1937).

${ }^{2}$ Cohen, H., and Davies, S., $J$. Anat., 62, 430 (1938)

${ }^{3}$ McClean, D., J. Path. and Bact., 33, 1045 (1930). 